\title{
Finite Element Analysis of Bearing Capacity of Reinforced Concrete Pipe Strengthened by TRC
}

\author{
Xinming Zhao ${ }^{1}$, Cheng $\mathrm{Kan}^{1 *}$, Yuxiao $\mathrm{Ye}^{2}$, Shaowei $\mathrm{Hu}^{3}$, Baibing Zhou ${ }^{2}$ \\ ${ }^{1}$ Nanjing University of Aeronautics and Astronautics, Nanjing, 210016, Jiangsu, China. \\ ${ }^{2}$ Nanjing Hydraulic Research Institute, Nanjing, 210024, Jiangsu, China. \\ ${ }^{3}$ CHONGQING University, Chongqing, 400000, China
}

\begin{abstract}
A non-linear 3D finite element model was established to simulate the three edge-bearing test of TRC reinforced concrete pipe. The pipe load-displacement curve, cracking load, and ultimate load simulation values are in good agreement with the test values. Subsequently, a parametric study was conducted. The effects of reinforcement layer bonding mode, mesh size of concrete element, mesh distribution rate and concrete compressive strength on the performance of reinforced concrete pipeline strengthened by TRC were considered. It provides a basis for the design of TRC reinforced concrete pipes.
\end{abstract}

\section{Page layout}

Reinforced concrete pipe plays an important role in urban drainage engineering. To meet crack and ultimate load design requirements, it is necessary to strengthen the long-serving reinforced concrete pipe. TRC reinforcement technology can be used to strengthen concrete members of any shape, and has been studied by scholars at home and abroad in recent years. Some scholars[1]pointed out that the use of TRC to reinforce reinforced concrete drainage pipes has certain research value.

At present, the three-edge-bearing test is widely used by the industry as a basis for the design check of concrete pipes, which often requires a lot of manpower and material resources. Therefore, some scholars proposed to use the finite element analysis method to design and research precast reinforced concrete pipes. Cheng et al[2]conducted a finite element simulation study of CFRP-reinforced PCCP pipes under TEBT testing. Mohanmed et al[3]reported a three-dimensional nonlinear numerical model for the design of steel fiber concrete pipe. The average error of the simulation results was within $6.5 \%$, which verified the rationality of the finite element-assisted design Ramadan et al. [4] established a finite element model for the design of SE (Elliptical Reinforced Cage) reinforced concrete pipes.

In this paper, the finite element model of TRC reinforced concrete pipeline under TEBT test is established based on CDP model. The model was validated using experimental data generated previously by the authors. Consequently, a parametric study is carried out by the validated model, which provides the basis for the design of TRC reinforced concrete pipeline.

\section{TEBT}

The TEBT test was conducted according to GB/T 15345 2017 (Standard Test Methods for Concrete Pipe). The upper supporting beam is a steel beam, and a rubber pad is placed between the steel beam and the pipe to avoid partial concrete crushing. The lower supporting beam is composed of two hardwoods with a spacing of $40 \mathrm{~mm}$.

The test results show that the failure mode of the pipe reinforced with TRC is ductile failure. The cracks first appear on the top of the pipe core concrete and the outer concrete of the pipe waist. TRC reinforced concrete pipes can increase the cracking load and ultimate load of the pipe.
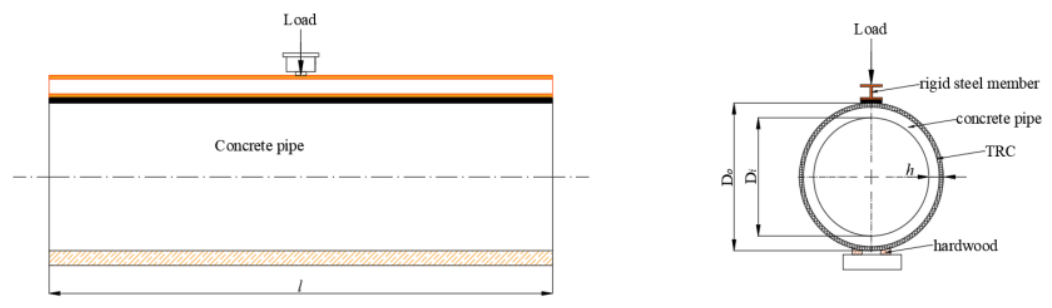

Fig. 1. Three edge bearing test setup

* Corresponding author: 18795886768@ $163 . c o m$ 


\section{Finite element modelling of TEBT}

A 3D model was established by ABAQUS to simulate TEBT test. Solid units (C3D8R in Abaqus Library) were used to simulate the concrete and polymer mortar, with a grid size of $14 \mathrm{~mm}$. The reinforcement and fabric mesh were simulated by T3D2 element. The upper and bottom support are simulated by discrete rigid body.

The interaction between the pipe barrel and the upper strip and lower strips was modeled using a simple tie constraint. Concrete and rebar, mortar and fabric are all embedded constraints Displacement controlled loading was accomplished by applying a $6 \mathrm{~mm}$ downward displacement at the upper bearing strip. The two lower bearing strips served as supports to the system and were fixed at their bottom face to prevent rotational or translational degrees of freedom.

Concrete and polymer mortar adopt CDP model[5]. Table 1 shows concrete CDP model parameters, Figure 3 shows the constitutive relation of concrete and motar. Table 2 shows the material parameters of rebar and fiber.

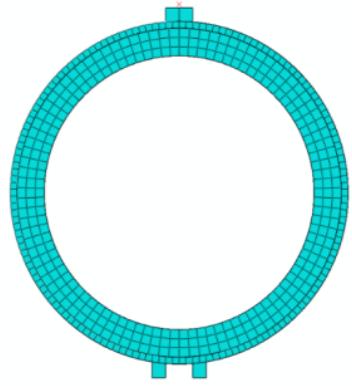

(a)

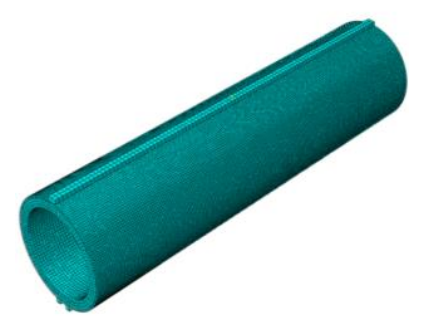

(b)

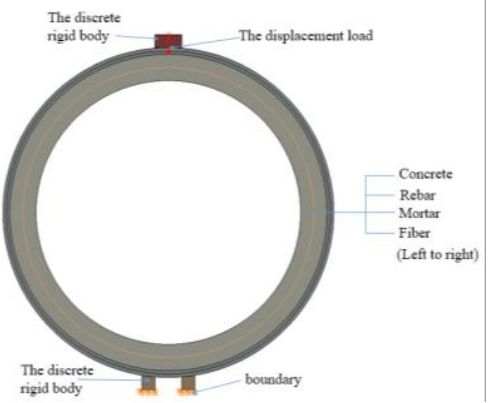

(c)

Fig. 2. Load-displacement curve comparison.

Table 1. Setting Word's margins.

\begin{tabular}{|c|c|}
\hline Parameter & value \\
\hline$\psi$ & 36.31 \\
\hline$K_{\mathrm{c}}$ & 0.1 \\
\hline$f_{\mathrm{b} 0} / f_{\mathrm{c} 0}$ & 1.16 \\
\hline $\mathrm{e}$ & 0.667 \\
\hline $\mathrm{V}$ & 0.0005 \\
\hline
\end{tabular}

Table 2. Mechanical properties of rebar and fibres.

\begin{tabular}{|c|c|c|}
\hline & $\begin{array}{c}\text { elasticity } \\
\text { modulus }\end{array}$ & $\begin{array}{c}\text { yield } \\
\text { strength }\end{array}$ \\
\hline fibre & $240 \mathrm{GPa}$ & $400 \mathrm{MPa}$ \\
\hline rebar & $200 \mathrm{GPa}$ & $300 \mathrm{MPa}$ \\
\hline
\end{tabular}

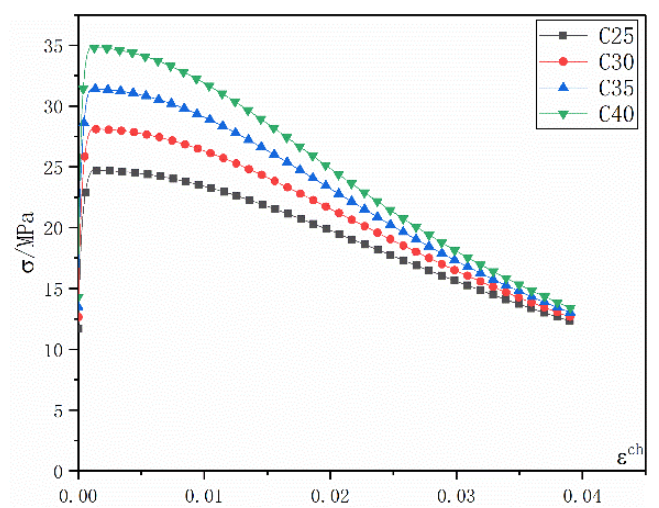

(a)

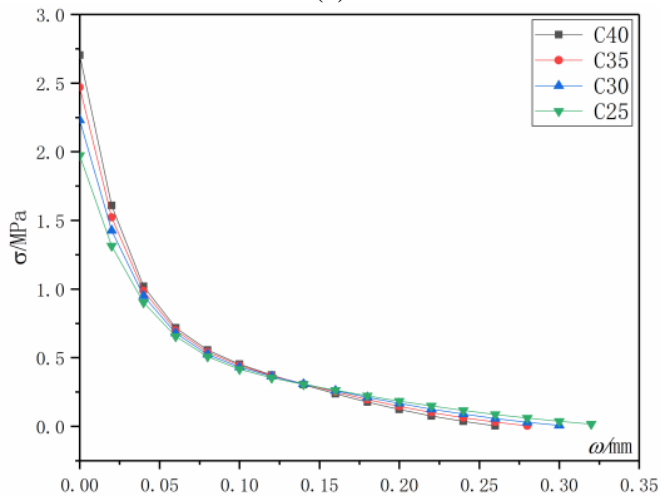

(b)

Fig. 3. Concrete constitutive in FE model.

\section{Model verification}

Fig. $4 \mathrm{a}$ is the stress nebula of the TRC reinforced concrete pipe. The failure pattern of the finite element simulation results of the pipeline is similar to the failure phenomenon observed in the test process. Fig. 4c shows the pipe deformation diagram simulated by the finite element method. The deformation shape of the pipeline simulated by the finite element method is similar to the shape observed in the test. As can be seen from the plastic damage cloud diagram of the pipeline in Fig. 4d, the phenomenon similar to the experimental results can be seen that the decrease in stiffness and tensile damage mainly occurred at the waist and top of the pipe.

The numerical results of the stiffness degradation SDEG and the tensile damage cloud map during the test are equal. It can be considered that the damage of the pipeline during the test is mainly caused by the tensile cracking of the outer concrete of the pipe body. The compression damage cloud map shows only the loading beam. Compression damage occurred to the nearby concrete unit, which was caused by local compression of the concrete during the test. Therefore, the tensile and 
compression properties of concrete elements should be changed in the subsequent parametric research, and the influence of concrete tensile properties on the simulation results should be discussed in detail.

It can be seen from Figure 5 that the overall trend of the pipeline load-displacement curve simulation value is consistent with the test value, but the overall simulation value is higher than the test value. There are three main reasons for this

- CDP model is used to calculate the concrete structure under the condition of low confining pressure. The pipe under the TEBT test condition is a plane strain problem which will bring confining pressure

- It is difficult to guarantee the symmetry of loading in the test process and the pipeline is damaged prematurely by eccentric load,

- The quality of the prefabricated pipe is poor, and its material strength index does not reach the parameters input by the finite element model.

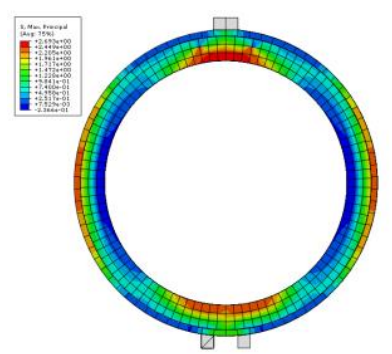

(a)stress nephogram

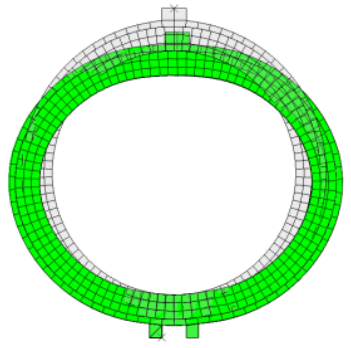

(c) deformation pattern

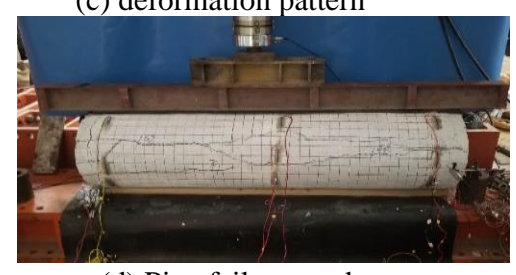

(d) Pipe failure mode

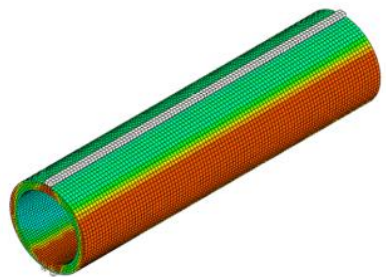

(b)stress nephogram

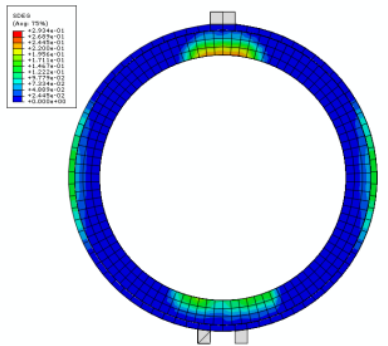

(d) SDEG

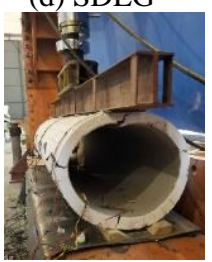

(e) Pipe failure mode
Fig. 4. The comparison of simulation and experimental.

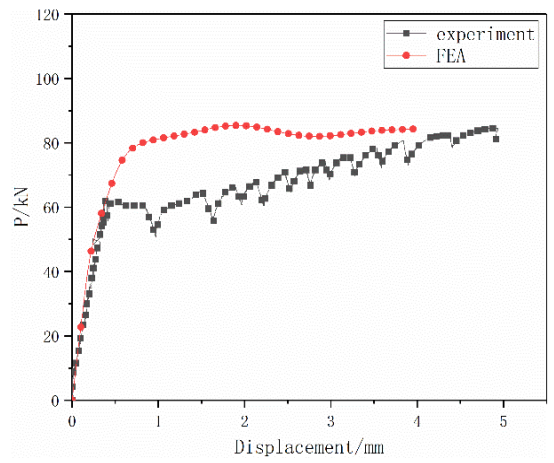

Fig. 5. Load-displacement curve comparison.
Fig $6 a$ is the load-tensile strain curve of the 0pipe-top pipe core concrete. It is considered that the load corresponding to the concrete tensile strain reaches 0.0001 is the cracking load, that is, the cracking load under the finite element simulation is $81 \mathrm{kN}$. From Fig $6 \mathrm{~b}$, the pipe-top pipe core concrete load-tension damage curve shows that when the pipe is loaded near the cracking load, the pipe-top pipe core concrete element just begins to release tensile damage, which further proves the rationality of the cracking load simulation value judgment.

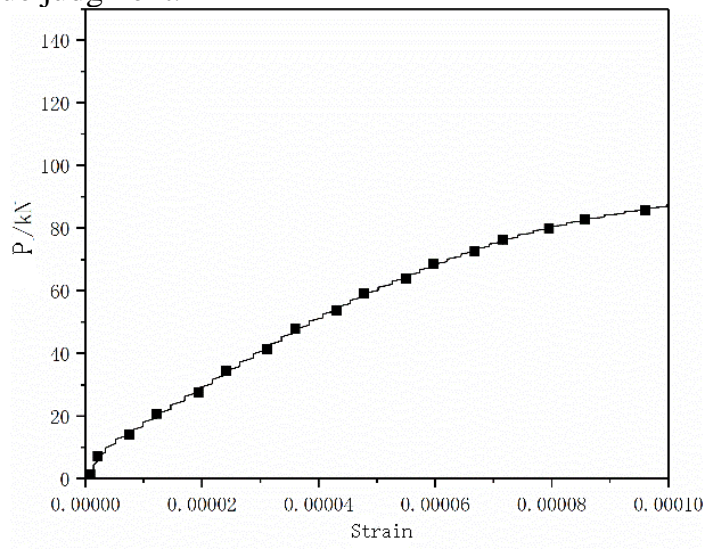

(a)The load-strain curve

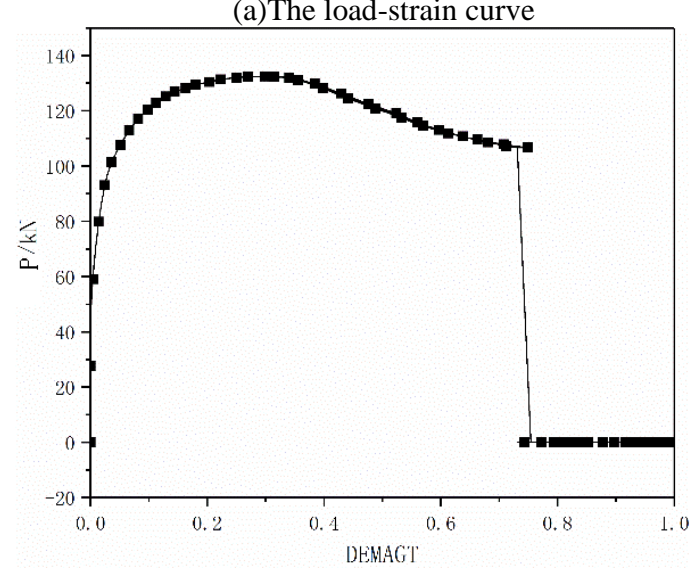

(b)The load - tension damage curve

Fig. 6. Load-displacement curve comparison.

Table 3 shows a comparative analysis table for the pipe cracking load and ultimate load bearing. It can be seen from Table 3 that the simulated values of the cracking load and ultimate load bearing capacity of the pipeline are both larger than the experimental values, and the error between the simulated bearing capacity and the experimental value is about $30 \%$. Considering the actual test conditions, it is within an acceptable range.

Table 3. Mechanical properties of rebar and fibres.

\begin{tabular}{|c|c|c|}
\hline & $\begin{array}{c}\text { Cracking } \\
\text { load }\end{array}$ & ultimate load \\
\hline simulation & 81 & 120 \\
\hline experiment & 62 & 92 \\
\hline error & $30 \%$ & $29 \%$ \\
\hline
\end{tabular}




\section{Parametric study}

Parameterization research using the verified model can provide reference for the practical application of TRC reinforced concrete pipeline. The main parameters to be considered include concrete tensile strength, concrete compressive strength, and reinforcement layer bonding mode.

Fig. 7a shows the influence of the tensile strength of concrete on the load-displacement curve of the pipe. In the initial stage of the curve, the tensile strength of concrete has little influence on the curve, and when it reaches the yield stage, the bearing capacity of the pipe increases with the increase of the tensile strength of concrete. Fig. $7 \mathrm{~b}$ shows the influence of concrete compressive strength on pipe load displacement curve. It can be seen from Fig. $7 b$ that the improvement of concrete compressive strength has little influence on pipe load bearing performance, and only has some influence on the curve trend in the unloading stage. Fig. 7c shows the influence of TRC tape sticking mode on the load-displacement curve of the pipe. The loaddisplacement curves are different in the elastic stage and the plastic stage due to the different sticking modes of the reinforcement layer, but the bearing capacity of the pipeline has little difference. Figure $7 d$ shows the influence of grid spacing on the load-displacement curve. From the trend of the curve, it can be analyzed that the grid spacing is $20-40 \mathrm{~mm}$, which has little effect on the calculation results. The optimal grid spacing is $20 \mathrm{~mm}$ from the analysis in the figure.

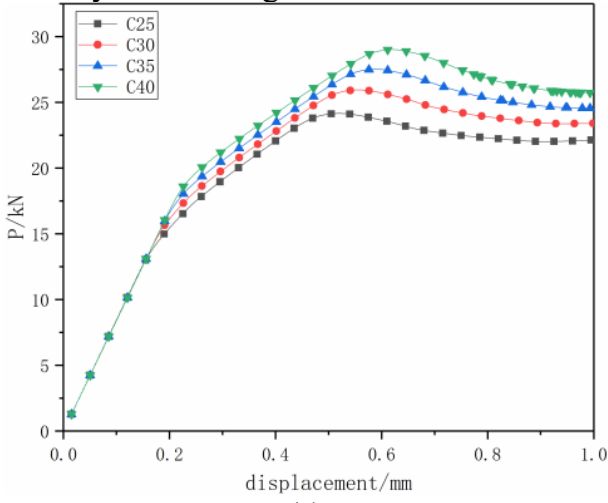

(a)

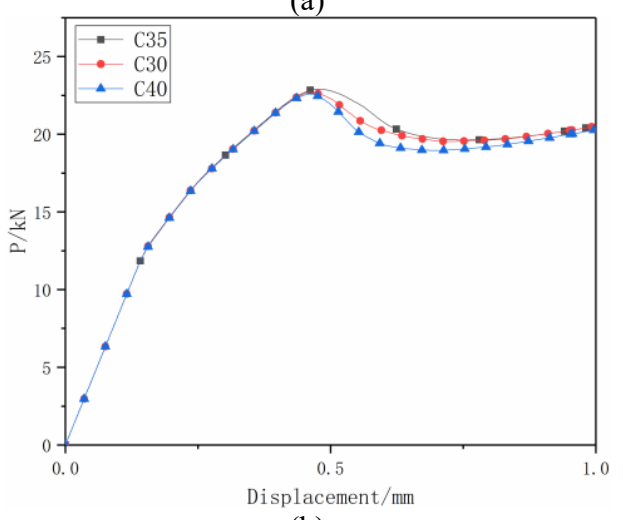

(b)

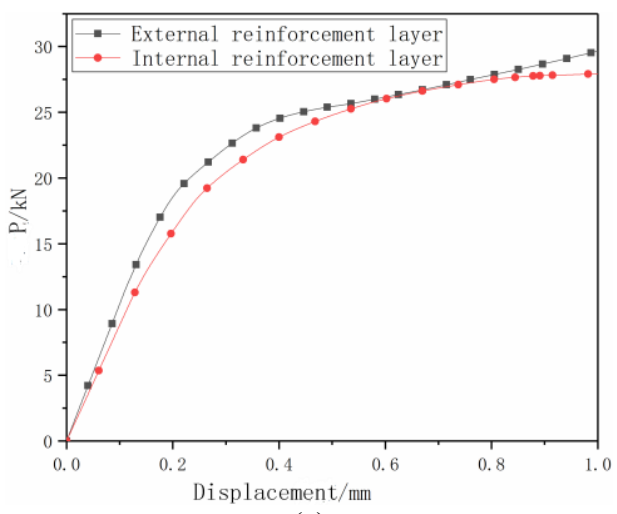

(c)

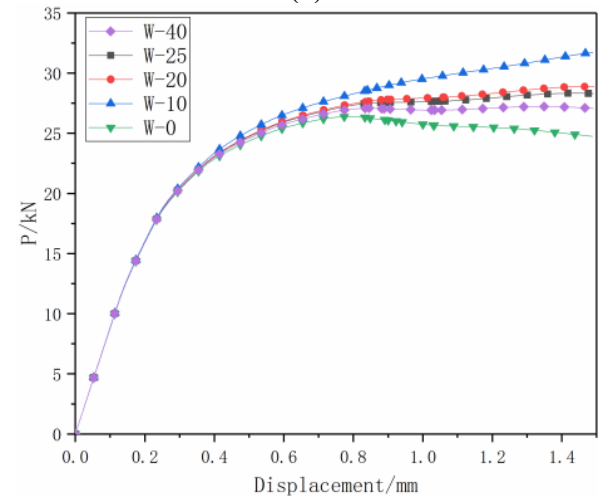

(d)

Fig. 7. Load-displacement curves for parametric studies

\section{Conclusions}

In this paper, a non-linear 3D finite element model was developed in order to simulate the three-edge-bearing test of TRC reinforced concrete pipe. Compare the simulated value of the model with the test results to verify the rationality of the model, and then conduct a parametric study on the model.

The results show that the error between the model simulation value and the test value is about $20 \%$, which can provide a basis for the design of TRC-reinforced reinforced concrete pipes. The tensile strength of concrete has a greater impact on the bearing performance of the pipe, and fiber can be added to the pipe concrete to increase its tensile capacity. The reinforcement layer pasted on the inner and outer walls of the pipe has little effect on the results, and the TRC reinforcement layer can be flexibly pasted in the actual construction.

\section{References}

1. Xun Yong. Summary of methods and mechanics principles of strengthening concrete. Journal of Yan cheng Institute of Technology 32, 1 5 (2003).

2. $\mathrm{He} \mathrm{Hu}$. Internal pressure test and numerical analysis of CFRP repairing prestressed concrete cylinder pipe. ( civil engineering, Beijing, 2017) .

3. Mohamed N, Nehdi M L M U. Rational finite element assisted design of precast steel fibre reinforced concrete pipes. Eng. Struct, 28, 96 206. (2016) 
4. Ramadan A, Shehata A, Younis A, et al. Modeling structural behavior of precast concrete pipe with single elliptical steel cage reinforcement. Eng. Struct, 18, 903 916 (2020).

5. Alfaraha B, López-Almansab F, Ollera S. New methodology for calculating damage variables evolution in Plastic Damage Model for RC structures. Eng. Struct, 32,70 86 (2017). 